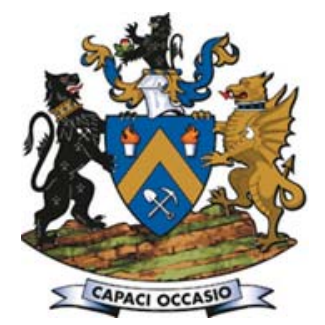

\title{
Evaluation of chromium (VI) removal by carbons derived from Sesamum indicum oil cake
}

\author{
by K.B. Nagashanmugam
}

\section{Synopsis}

Activated carbons were prepared from gingelly oil cake (GOC) by thermal, sulpuric acid, and zinc chloride activation methods and their $\mathrm{Cr}$ (VI) removal capacities compared with that of commercial activated carbon (CAC). The effect of experimental parameters such as $\mathrm{pH}$, initial $\mathrm{Cr}(\mathrm{VI})$ concentration, contact time, and adsorbent dose for $\mathrm{Cr}(\mathrm{VI})$ removal were studied. Langmuir and Freundlich models were tested to describe the equilibrium isotherms. The maximum adsorption capacities of the adsorbents calculated from Langmuir isotherm were found to be $88.68 \mathrm{mg} / \mathrm{g}, 109.89 \mathrm{mg} / \mathrm{g}, 101.01 \mathrm{mg} / \mathrm{g}$, and $84.03 \mathrm{mg} / \mathrm{g}$ for thermal activated (TAGOC), sulphuric acid treated (STGOC), zinc chloride treated GOC (ZTGOC), and CAC respectively. $\mathrm{R}^{2}$ values show that both Langmuir and Freundlich models fit well to explain the adsorption by TAGOC, STGOC, ZTGOC, and CAC. The kinetic data fits best to a pseudo second-order model. The studies demonstrated effective removal of $\mathrm{Cr}(\mathrm{VI})$ from chrome plating wastewater.

Keywords

$\mathrm{Cr}$ (VI) removal, activated carbon, gingelly oil cake, adsorption isotherms, kinetics, chrome plating wastewater.

\section{Introduction}

Among the heavy metals, chromium is a common and very toxic pollutant introduced into natural waters from a variety of industrial wastewaters (Donmez and Aksu, 2002). Hexavalent chromium, primarily present in the form of chromate $\left(\mathrm{CrO}_{4}^{2-}\right)$ and dichromate $\left(\mathrm{Cr}_{2} \mathrm{O}_{7}^{2-}\right)$, poses significantly higher levels of toxicity than the other valence states (Sharma and Forster, 1995). The recommended limit of $\mathrm{Cr}(\mathrm{VI})$ in potable water is only $0.05 \mathrm{mg} / \mathrm{L}$ (Baran et al., 2006). Studies reveal that human exposure to water contaminated with hexavalent chromium leads to gastrointestinal and dermatological complaints and abnormal hematological functions (de Brito et al., 2004). Thus treatment of the effluent to reduce or remove the pollutant before discharging into the environment becomes imperative (Baral, Dasa, and Rath, 2006; Debnath and Ghosh, 2008). A number of methods have been developed for the removal of $\mathrm{Cr}(\mathrm{VI})$ from wastewater, such as chemical precipitation (Jamalledin and Husein, 2008), ion exchange (Erden, Karapinar, and Donat, 2004), electrodialysis (Velizarova, Ribeiro, and Ottosen, 2002), and reverse osmosis (Zou et al., 2009). However, these methods suffer from disadvantages such as the generation of large volumes of sludge, and high capital investment and running costs (Ahalya, Ramachandra, and Kanamadi, 2003).

Adsorption is a technique that would be more viable and economical (Rodrigues and Silva, 2009). Several adsorbents have been developed and tested, ranging from low-cost materials such as coffee husk (Ahalya, Kanamadi, and Ramachandra, 2010), cow dung (Das et al., 2000), coconut shell (Alaerts, Jitjaturunt, and Kelderman, 1989), rice husk carbon (Srinivasan, Balasubramanian, and Ramakrishna, 1988), neem oil cake (Srinivasan and Hema, 2009), coconut oil cake (Hema and Srinivasan, 2010), mustard oil cake (Rao, Khan, and Jeon, 2010), fertilizer waste (Srivastava, Gupta, and Mohan, 1996; Gupta, Rastogi, and Nayak, 2010), green algae (Gupta, Srivastava, and Jain, 2001), butter oil cake (Rukmangathan and Kumar, 2009), jatropha oil cake (Umesh et al., 2007), olive oil cake (Dakiki et al., 2002), and soya cake (Daneshwar, Salari, and Aber, 2002) to more sophisticated adsorbents such as zeolites (Groffman, Peterson, and Brookins, 1992), carbon cloths (Kadirvelu, Faur-Brasquet, and le Cloirec, 2000), carbon aerogels (Kadirvelu, Goel, and Rajagopal, 2008), cotton stalks (Li, Zheng, and Li, 2010), graphene layers (Machida, Mochimaru, and Tatsumoto, 2006), polymers (Pandey, Anupam., and Ray, 2009), carbon fibres (Park and Jung, 2001), and carbon nanotubes (Perez-Aguilar et al., 2010).

The objective of the present study is to investigate the adsorption potential of carbons derived from gingelly oil cake (GOC) by thermal, sulphuric acid, and zinc chloride activation for the removal of $\mathrm{Cr}(\mathrm{VI})$ from aqueous solutions and chrome plating wastewater and to compare the performance of the carbons with commercial activated carbon. The optimum adsorption conditions were

\footnotetext{
* Head TQA Emmar Steel Melting Hassia, Syria.

(C) The Southern African Institute of Mining and Metallurgy, 2018. ISSN 2225-6253. Paper received Jan. 2016; revised paper received Mar. 2018.
} 


\section{Evaluation of chromium (VI) removal by carbons derived from Sesamum indicum oil cake}

evaluated as a function of contact time, $\mathrm{pH}$, adsorbent dose, and initial $\mathrm{Cr}(\mathrm{VI})$ concentration. Adsorption isotherm, kinetic, and desorption studies were also conducted to understand the adsorption phenomenon.

\section{Description of work and methodology}

\section{Preparation of thermally activated gingelly oil cake carbon (TAGOC)}

$20 \mathrm{~g}$ of washed and sun-dried GOC was placed in a silica crucible and carbonized slowly in a muffle furnace at a temperature of $600-700^{\circ} \mathrm{C}$. At this temperature, GOC begins to char with the evolution of fumes. As soon as the production of char was complete (indicated by the absence of fumes), the furnace temperature was raised slowly to 800 $850^{\circ} \mathrm{C}$ for thermal activation under an inert atmosphere of nitrogen for a period of 30 minutes (Hassler, 1974).

\section{Preparation of sulphuric acid-treated gingelly oil cake carbon (STGOC)}

$50 \mathrm{~g}$ of washed and sun-dried GOC was mixed with $200 \mathrm{~g}$ (1:4 ratio by weight) of concentrated sulphuric acid. The mixing was done by adding small quantities of oil cake to acid in a $1000 \mathrm{~mL}$ beaker with vigorous stirring. Charring of the cake occurs immediately, accompanied by the evolution of fumes. When the reaction subsided, the mixture was left in air in the oven at $140-160^{\circ} \mathrm{C}$ for 24 hours. The product was then washed with approximately 4.0-4.5 L of distilled water to remove free sulphuric acid, and dried at $110^{\circ} \mathrm{C}$ (Kannan and Thambidurai, 2008).

\section{Preparation of zinc chloride-treated gingelly oil cake carbon (ZTGOC)}

$20 \mathrm{~g}$ of washed and sun-dried GOC was soaked in a $20 \%$ solution of $\mathrm{ZnCl}_{2}$ for 24 hours. The solution was then decanted off. The wet oil cake was spread uniformly on a glass plate and dried at $110^{\circ} \mathrm{C}$. The dried material was heated slowly to a temperature of $600^{\circ} \mathrm{C}$, followed by thermal activation under nitrogen atmosphere at $800-850^{\circ} \mathrm{C}$ for 30 minutes in a muffle furnace. The carbonized material was washed with $250-300 \mathrm{~mL}$ of distilled water and then with $15-20 \mathrm{~mL}$ of $10 \% \mathrm{HCl}$ to remove excess zinc chloride from the carbon surface. It was then washed with water and dried at $110^{\circ} \mathrm{C}$ (Acharya et al., 2009).

The physicochemical analyses of the adsorbents were carried out as per standard procedures, and the characteristics are given in Table I.

GOC carbons thus prepared and commercial activated carbon (CAC) from SD Fine Chem., Mumbai, India were powdered and sieved to a particle size of $80-120$ mesh (ASTM) and used for further experiments.

\section{Preparation of $\mathrm{Cr}(\mathrm{VI})$ solutions}

A stock aqueous solution of $\mathrm{Cr}(\mathrm{VI})$ at a concentration of $1000 \mathrm{mg} / \mathrm{L}$ was prepared by dissolving $2.829 \mathrm{~g}$ of $\mathrm{K}_{2} \mathrm{Cr}_{2} \mathrm{O}_{7}$ in $1000 \mathrm{~mL}$ of distilled water. $\mathrm{Cr}(\mathrm{VI})$ solutions of desired concentrations were prepared by dilution of the stock solution with distilled water.

\section{Adsorption studies}

In all sets of experiments, $100 \mathrm{~mL}$ of $\mathrm{Cr}(\mathrm{VI})$ solution at the desired concentration and adjusted to the desired $\mathrm{pH}$ was decanted into high-density polyethylene (HDPE) bottles of $300 \mathrm{~mL}$ capacity and the desired dose of adsorbent added. The solution $\mathrm{pH}$ was adjusted with $0.1 \mathrm{M} \mathrm{HNO}_{3}$ or $\mathrm{KOH}$. The solutions were agitated for various contact times at $30 \pm 1^{\circ} \mathrm{C}$ and carbon particles were separated by using a centrifuge at a speed of $500 \mathrm{r} / \mathrm{min}$. The supernatant liquid was analysed for $\mathrm{Cr}(\mathrm{VI})$ by atomic absorption spectrometry (AAS). Before determination of the total quantity of $\mathrm{Cr}(\mathrm{VI})$ in the adsorption medium, the supernatant liquid after adsorption was digested with $\mathrm{KMnO}_{4}$ in sulphuric acid medium to oxidize any $\mathrm{Cr}$ (II) and $\mathrm{Cr}$ (III) to $\mathrm{Cr}$ (VI) (Gupta, Rastogi, and Nayak, 2010). Solute and adsorbent-free blanks were used as control in all the experiments. Adsorption isotherm and kinetic studies

Table I

Physicochemical characteristics of the activated carbons

\begin{tabular}{|c|c|c|c|c|}
\hline Parameter & TAGOC & STGOC & ZTGOC & CAC \\
\hline $\begin{array}{l}\text { Matter soluble in water }(\%) \\
\text { Matter soluble in acid }(\%) \\
\text { Bulk density }\left(\mathrm{g} / \mathrm{cm}^{3}\right) \\
\mathrm{pH} \\
\mathrm{Fe}(\%) \\
\text { Decolourizing power }(\mathrm{mg} / \mathrm{g}) \\
\text { lon-exchange capacity }(\mathrm{m} \text { equiv/g) } \\
\text { Phenol number } \\
\text { BET surface area }\left(\mathrm{m}^{2} / \mathrm{g}\right) \\
\text { Total pore volume }\left(\mathrm{cm}^{3} / \mathrm{g}\right) \\
\text { Average pore size }(\AA)\end{array}$ & $\begin{array}{r}7.10 \\
44.10 \\
0.84 \\
11.30 \\
0.62 \\
30.00 \\
- \\
62.00 \\
14.30 \\
0.04 \\
117.34\end{array}$ & $\begin{array}{r}0.84 \\
4.90 \\
0.79 \\
3.70 \\
0.28 \\
33.10 \\
0.72 \\
57.00 \\
6.78 \\
0.02 \\
89.56\end{array}$ & $\begin{array}{r}12.23 \\
17.67 \\
0.80 \\
2.80 \\
0.59 \\
75.20 \\
1.15 \\
48.00 \\
333.93 \\
0.22 \\
25.88\end{array}$ & $\begin{array}{r}4.50 \\
9.20 \\
0.74 \\
7.60 \\
0.18 \\
90.00 \\
- \\
35.00 \\
558.02 \\
0.32 \\
2.88\end{array}$ \\
\hline $\begin{array}{l}\text { Proximate analysis } \\
\text { Moisture (\%) } \\
\text { Volatile matter (\%) } \\
\text { Ash (\%) } \\
\text { Fixed carbon }(\%)\end{array}$ & $\begin{array}{r}3.21 \\
18.91 \\
34.94 \\
46.15\end{array}$ & $\begin{array}{r}2.30 \\
43.30 \\
4.95 \\
51.75\end{array}$ & $\begin{array}{r}13.20 \\
37.85 \\
9.52 \\
52.63\end{array}$ & $\begin{array}{r}3.70 \\
12.73 \\
1.19 \\
86.08\end{array}$ \\
\hline $\begin{array}{l}\text { Elemental analysis } \\
\text { Carbon }(\%) \\
\text { Sulphur }(\%) \\
\text { Nitrogen }(\%) \\
\text { Oxygen }(\%)\end{array}$ & $\begin{array}{r}46.90 \\
1.01 \\
0.94 \\
13.35\end{array}$ & $\begin{array}{r}53.42 \\
3.26 \\
2.72 \\
15.59\end{array}$ & $\begin{array}{r}52.60 \\
1.57 \\
2.74 \\
12.43\end{array}$ & $\begin{array}{r}85.90 \\
0.22 \\
0.11 \\
4.99\end{array}$ \\
\hline
\end{tabular}




\section{Evaluation of chromium (VI) removal by carbons derived from Sesamum indicum oil cake}

were carried out with different initial concentrations of $\mathrm{Cr}(\mathrm{VI})$ by maintaining a constant adsorbent dose. Adsorption isotherm studies were conducted after equilibrating the solution for 24 hours. The concentration of unadsorbed $\mathrm{Cr}(\mathrm{VI})$ in the supernatant liquid was determined by AAS with an air-acetylene flame. The hollow cathode lamp was operated at $15 \mathrm{~mA}$ and the analytical wavelength was set at $358 \mathrm{~nm}$. The removal efficiency $(E)$ of the adsorbents on $\mathrm{Cr}(\mathrm{VI})$ was calculated by the following expression.

$$
E(\%)=\frac{\left(C_{o}-C_{e}\right)}{C_{o}} \times 100
$$

where $C_{o}$ and $C_{e}$ are the initial and equilibrium concentrations $(\mathrm{mg} / \mathrm{L})$ of $\mathrm{Cr}(\mathrm{VI})$ solution respectively.

\section{Results and discussion}

\section{Effect of contact time}

In order to investigate the effect of equilibration time on $\mathrm{Cr}$ (VI) removal, experiments were carried out using $100 \mathrm{~mL}$ of solution containing $10 \mathrm{mg} / \mathrm{L} \mathrm{Cr}(\mathrm{VI})$ and $0.3 \mathrm{~g}$ of carbon at $\mathrm{pH}$ 2.0. A set of solutions was equilibrated for periods ranging from 1 to 4 hours. After agitation, the solutions were centrifuged, analysed, and the percentage of $\mathrm{Cr}(\mathrm{VI})$ removed in each case was established. The results are presented in Figure 1.

It is observed from the graph that equilibration times of 3 hours and 2.5 hours were required for the maximum chromium(VI) removals of $88.0 \pm 0.3 \%$ and $89.2 \pm 0.3 \%$ by CAC and TAGOC respectively. However, 2 hours' equilibration time was sufficient for both STGOC and ZTGOC for a maximum chromium(VI) removal of $96.0 \pm 0.3 \%$ and $94.0 \pm 0.3 \%$ respectively. These results indicate that both STGOC and ZTGOC take much less time (33.33\% less) than $\mathrm{CAC}$ to reach equilibrium. Hence, all further experiments were carried out at the optimum equilibration times of 3 hours and 2.5 hours for CAC and TAGOC, and 2 hours for both STGOC and ZTGOC.

\section{Effect of $\mathrm{pH}$}

In order to ascertain the optimum $\mathrm{pH}$ for maximum removal of $\mathrm{Cr}(\mathrm{VI})$, experiments were carried out by varying the $\mathrm{pH}$ of the solution over the range of 1.0 to 9.0. After equilibration, the solutions were analysed and the percentage of $\mathrm{Cr}(\mathrm{VI})$ removal was established. The results are presented in Figure 2.

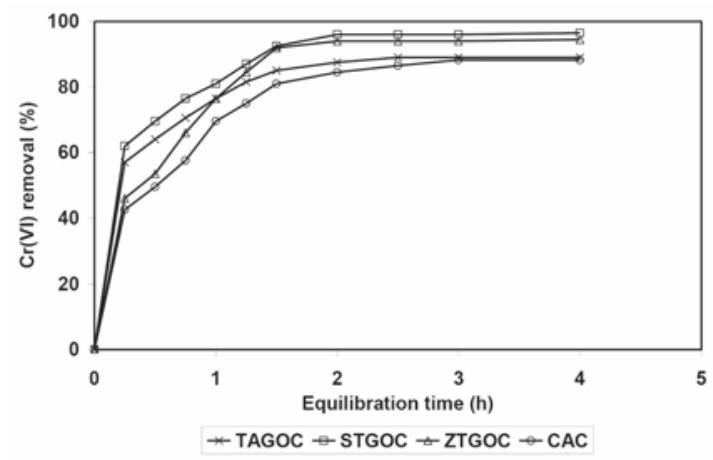

Figure 1-Effect of equilibration time on $\mathrm{Cr}(\mathrm{VI})$ removal. [Cr(VI)] $10 \mathrm{mg} / \mathrm{L}$, adsorbent dose $0.3 \mathrm{~g} / 100 \mathrm{~mL}, \mathrm{pH} 2.0 \pm 0.1$
It is observed that maximum removal of $\mathrm{Cr}(\mathrm{VI})$ occurs at lower $\mathrm{pH}$, and as the $\mathrm{pH}$ increases the removal of $\mathrm{Cr}(\mathrm{VI})$ decreases. Lower $\mathrm{pH}$ increases the positive charge on the adsorbent surface and thus the attraction for the negatively charged chromium species in solution increases. The maximum adsorption for TAGOC, STGOC, ZTGOC, and CAC occurs at pH 2.0, 2.5, 2.5, and 1.5 respectively. This indicates that STGOC, ZTGOC, and TAGOC remove $\mathrm{Cr}(\mathrm{VI})$ at higher $\mathrm{pH}$ values compared to $\mathrm{CAC}$. Hence all further experiments were carried out at an optimum pH of 2.0 for TAGOC, 2.5 for STGOC and ZTGOC, and 1.5 for CAC. Under these conditions, for an initial concentration of $10 \mathrm{mg} / \mathrm{L}$, the maximum removals achieved by TAGOC, STGOC, ZTGOC, and CAC are $89 \pm 0.3 \%, 96.0 \pm 0.3 \%, 94.0 \pm 0.3 \%$, and $88.0 \pm 0.3 \%$ respectively. These results indicate that TAGOC, STGOC, and ZTGOC are superior to CAC in the removal of $\mathrm{Cr}(\mathrm{VI})$, and also that they are effective at higher $\mathrm{pH}$ values than CAC.

\section{Effect of adsorbent dose}

In order to ascertain the minimum amount of each carbon type required for maximum removal of chromium(VI), experiments were carried out with $100 \mathrm{~mL}$ of $10 \mathrm{mg} / \mathrm{L}$ chromium(VI) solution in the presence of varying amounts of carbon ranging from $0.05-0.6 \mathrm{~g} / 100 \mathrm{~mL}$ at an optimum $\mathrm{pH}$ of 2.0 for TAGOC, 2.5 for STGOC and ZTGOC, and 1.5 for CAC. Respective equilibration times were maintained for these carbons and the chromium(VI) removal in each instance was established. The results are presented in Figure 3.

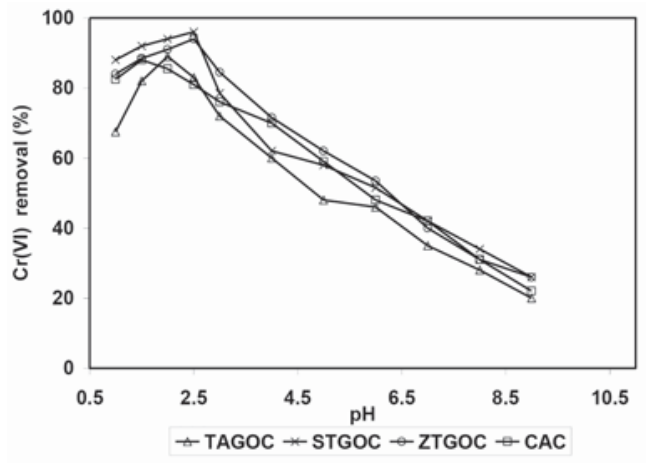

Figure 2-Effect of $\mathrm{pH}$ on $\mathrm{Cr}(\mathrm{VI})$ removal. [Cr(VI)] $10 \mathrm{mg} / \mathrm{L}$, equilibrated time $2.5 \mathrm{~h}$ for TAGOC, $2 \mathrm{~h}$ for STGOC and ZTGOC, and $3 \mathrm{~h}$ for CAC, adsorbent dose $0.3 \mathrm{~g} / 100 \mathrm{~mL}$

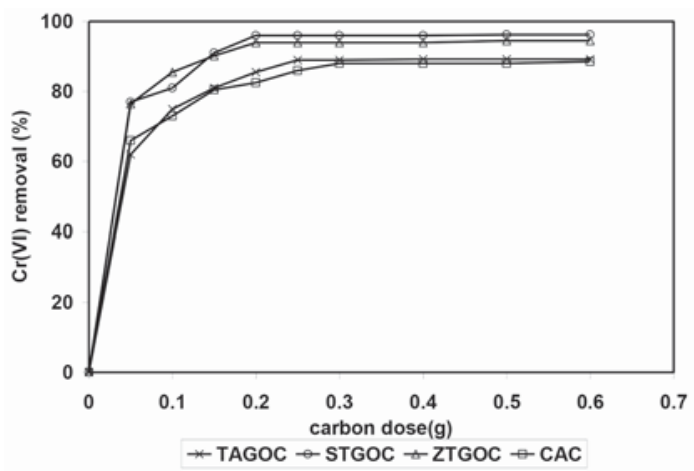

Figure 3-Effect of carbon dose on $\mathrm{Cr}(\mathrm{VI})$ removal. [Cr( $\mathrm{VI})] 10 \mathrm{mg} / \mathrm{L}$, equilibrated time $2.5 \mathrm{~h}$ for TAGOC, $2 \mathrm{~h}$ for STGOC and ZTGOC, and $3 \mathrm{~h}$ for CAC, pH 2.0 \pm 0.1 for TAGOC, $2.5 \pm 0.1$ for STGOC and ZTGOC, $1.5 \pm 0.1$ for CAC 


\section{Evaluation of chromium (VI) removal by carbons derived from Sesamum indicum oil cake}

It is seen that minimum carbon doses of $0.25 \mathrm{~g}$ per $100 \mathrm{~mL}$ for TAGOC, and $0.2 \mathrm{~g}$ per $100 \mathrm{ml}$ for STGOC and ZTGOC were sufficient for the removal of $89.2 \pm 0.3 \%$, $96.0 \pm 0.3 \%$, and $94.0 \pm 0.5 \%$ of chromium(VI). However, in the case of CAC a minimum carbon dose of $0.3 \mathrm{~g}$ per $100 \mathrm{~mL}$ was required for the removal of $88.0 \pm 0.3 \%$ of chromium(VI). This indicates that TAGOC requires 1.2 times less carbon, and both STGOC and ZTGOC require 1.5 times less carbon, than that required for $\mathrm{CAC}$ under optimum time and $\mathrm{pH}$ conditions. Hence, based on optimization studies, it appears that TAGOC, STGOC, and ZTGOC could serve as better adsorbents than $\mathrm{CAC}$ in the removal of $\mathrm{Cr}(\mathrm{VI})$ from aqueous solutions.

\section{Adsorption isotherms}

Adsorption isotherms can be used to describe how solutes interact with adsorbents and so are critical in optimizing the use of adsorbents. The commonly used isotherms such as the Langmuir and Freundlich isotherms were applied for this study. The linear form of the Langmuir equation is given as (Langmuir, 1918)

$$
1 / q_{e}=1 / \mathrm{b}+1 / \mathrm{ab} \cdot C_{e}
$$

where $C_{e}$ is the equilibrium concentration $(\mathrm{mg} / \mathrm{L}), q_{e}$ is the amount of $\mathrm{Cr}(\mathrm{VI})$ adsorbed at equilibrium (mg/g), and ' $\mathrm{a}$ ' and ' $b$ ' are Langmuir constants related to energy of adsorption (mg-1) and adsorption capacity (mg/g) respectively. The plot of $1 / q_{e}$ versus $1 / C_{e}$ gives a straight line. Figure 4 shows the Langmuir adsorption isotherms for adsorption of $\mathrm{Cr}(\mathrm{VI})$ onto these adsorbents after an equilibration time of 24 hours. Langmuir constants ' $a$ ' and 'b' were determined from the slopes and intercepts, and the values are presented in Table II.

The maximum adsorption capacities of the adsorbents calculated from Langmuir isotherms were found to be $88.68 \mathrm{mg} / \mathrm{g}, 109.89 \mathrm{mg} / \mathrm{g}, 101.01 \mathrm{mg} / \mathrm{g}$, and $84.03 \mathrm{mg} / \mathrm{g}$ for TAGOC, STGOC, ZTGOC, and CAC respectively. A dimensionless constant, the separation factor $\left(R_{L}\right)$, can be used to predict whether a sorption system is favourable or otherwise in batch adsorption. $\mathrm{R}_{\mathrm{L}}$ values ranging between 0 and 1 generally indicate favorable adsorption. $\mathrm{R}_{\mathrm{L}}$ values were calculated from Langmuir isotherm-based equation:

$$
R_{L}=\frac{1}{\left(1+a C_{o}\right)}
$$

where $C_{0}$ is the initial concentration of $\mathrm{Cr}(\mathrm{VI})$ and ' $\mathrm{a}$ ' is the Langmuir constant, which represents energy of adsorption.

The $R_{L}$ value indicates the nature of adsorption process and the process could be favourable, irreversible, linear, and

\begin{tabular}{|l|c|c|c|}
\hline $\begin{array}{l}\text { Table /I } \\
\text { Langmuir adsorption isotherm constants }\end{array}$ \\
\hline Carbon & $\begin{array}{c}\text { Adsorption energy } \\
\boldsymbol{a}(\mathbf{m g}-\mathbf{1})\end{array}$ & $\begin{array}{c}\text { Adsorption capacity } \\
\boldsymbol{b}(\mathbf{m g} / \mathbf{g})\end{array}$ & $\mathbf{R}^{\mathbf{2}}$ \\
& 0.08 & 88.68 & \\
\hline TAGOC & 0.10 & 109.89 & 0.9893 \\
STGOC & 0.25 & 101.01 & 0.9997 \\
ZTGOC & 0.34 & 84.03 & 0.9848 \\
CAC & & &
\end{tabular}

unfavourable when $0<R_{L}<1, R_{L}=0, R_{L}=1$, and $R_{L}>1$ respectively. The $R_{L}$ values for TAGOC, STGOC, ZTGOC, and CAC were found to be between 0 and 1 at all concentrations investigated, which shows that the sorption of $\mathrm{Cr}(\mathrm{VI})$ onto these adsorbents is favourable.

The linear form of the Freundlich isotherm is represented by the following equation (Freundlich and Helle, 1939):

$$
\log \frac{x}{m}=\log K_{F}+\frac{1}{n}\left(\log C_{e}\right)
$$

where $C_{e}$ is the equilibrium concentration $(\mathrm{mg} / \mathrm{L})$ and $x / m$ is the amount adsorbed per unit weight of adsorbent $(\mathrm{mg} / \mathrm{g})$. The plot of $\log (x / m)$ versus $\log C_{e}$ gives a straight line, which indicates favorable adsorption. Figure 5 shows Freundlich adsorption isotherms for adsorption of $\mathrm{Cr}(\mathrm{VI})$ onto these adsorbents. The $K_{F}$ and $n$ values were calculated from the intercepts and slopes, respectively. The values of adsorption capacity $\left(K_{F}\right)$, adsorption intensity $(n)$, and correlation coefficient $\left(\mathrm{R}^{2}\right)$ are presented in Table III. The plot of $\log x / \mathrm{m}$ $v s \log C_{e}$ gives a straight line with a slope of $1 / n$ and $\log K_{F}$ is the intercept of $\log x / m$ at $\log C_{e}=0\left(C_{e}=1\right)$. The straight line nature of the plots indicates that the process was of

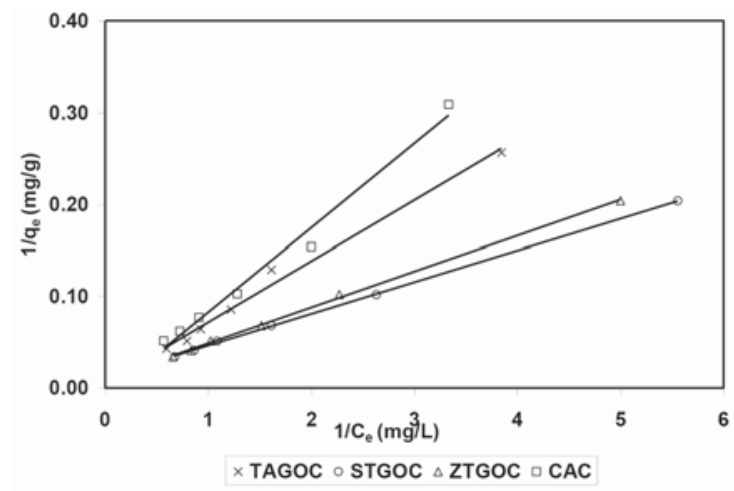

Figure 4-Langmuir adsorption isotherms for $\mathrm{Cr}(\mathrm{VI})$ in distilled water. $T=30 \pm 2^{\circ} \mathrm{C},[\mathrm{Cr}(\mathrm{VI})] 10-60 \mathrm{mg} / \mathrm{L}$, equilibration time $-24 \mathrm{~h}, \mathrm{pH} 2.0 \pm 0.1$ for TAGOC, $2.5 \pm 0.1$ for STGOC and ZTGOC, and $1.5 \pm 0.1$ for CAC, adsorbent dose $0.25 \mathrm{~g}$ per $100 \mathrm{~mL}$ for TAGOC, $0.2 \mathrm{~g}$ per $100 \mathrm{~mL}$ for STGOC and ZTGOC, $0.3 \mathrm{~g}$ per $100 \mathrm{~mL}$ for CAC

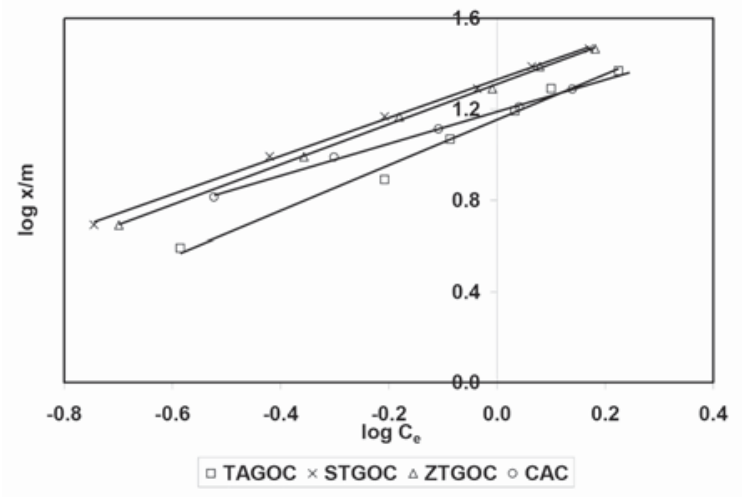

Figure 5-Freundlich adsorption isotherms for $\mathrm{Cr}(\mathrm{VI})$ in distilled water. $T 30 \pm 2^{\circ} \mathrm{C},[\mathrm{Cr}(\mathrm{VI})] 10-60 \mathrm{mg} / \mathrm{L}$, equilibration time $24 \mathrm{~h}, \mathrm{pH} 2.0 \pm 0.1$ for TAGOC, $2.5 \pm 0.1$ for STGOC and TGOC, $1.5 \pm 0.1$ for CAC, adsorbent dose $0.25 \mathrm{~g}$ per $100 \mathrm{~mL}$ : for TAGOC, $0.2 \mathrm{~g}$ per $100 \mathrm{~mL}$ for STGOC and ZTGOC, $0.3 \mathrm{~g}$ per $100 \mathrm{~mL}$ for CAC 


\section{Evaluation of chromium (VI) removal by carbons derived from Sesamum indicum oil cake}

Freundlich adsorption type. The $K_{F}$ values of the Freundlich adsorption equation were obtained for TAGOC, STGOC, ZTGOC, and CAC from the intercept on the $\log x / m$ axis. The sorption intensities ' $1 / n$ ' were obtained for all the carbons from the slopes of the curves.

The values of adsorption intensity, ranging between 1 and $10(1<n<10)$, generally indicate favourable adsorption. The ' $n$ ' values were found to be between 1 and 10, which shows that adsorption of $\mathrm{Cr}(\mathrm{VI})$ onto these adsorbents is favourable.

Correlation coefficient $\left(\mathrm{R}^{2}\right)$ values were determined for the linear plots obtained for both the isotherm models and are presented in Tables II and III. From the $\mathrm{R}^{2}$ values, it may be concluded that both the Langmuir and Freundlich adsorption isotherms operate simultaneously on the surface of carbon adsorbents in the removal of $\mathrm{Cr}(\mathrm{VI})$ from aqueous solutions.

\section{Adsorption kinetics}

In order to clarify the adsorption kinetics of $\mathrm{Cr}(\mathrm{VI})$ ions onto these adsorbents, two kinetic models, Lagergren's pseudofirst order and pseudo-second order models, were applied to the experimental data.

The linearized form of the pseudo-first order rate equation of Lagergren is given as (Lagergren, 1898)

$$
\ln \left(q_{e(\exp )}-q_{t(\exp )}\right)=\ln q_{e(\text { theo })}-k_{l} t
$$

where $q_{e}(\exp )$ and $q_{t}(\exp )$ are the amount of the metal ions adsorbed $(\mathrm{mg} / \mathrm{g})$ at equilibrium and at time $t(\mathrm{~min})$, respectively and $k_{1}$ is the pseudo-first order equilibrium rate constant $\left(\min ^{-1}\right)$. A plot of $\ln \left(q_{e}(\exp )-q_{t}(\exp )\right)$ versus $t$ gives a straight line with slope of $k_{1}$ and an intercept of $\ln q_{e(t h e o)}$. The straight line nature of curve shows the applicability of pseudo-first order rate equation. Figures 6-9 present pseudofirst order kinetics for the adsorption of $\mathrm{Cr}(\mathrm{VI})$ onto TAGOC, STGOC, ZTGOC, and CAC respectively.

The pseudo-second order model rate equation may be expressed as (Ho and McKay, 1999)

$$
\frac{t}{q_{t(\exp )}}=\frac{1}{k_{2} q_{e(\text { theo })}^{2}}+\frac{t}{q_{e(\text { theo })}}
$$

where $k^{2}$ is the pseudo-second order adsorption rate constant $\left(\mathrm{g} / \mathrm{mg} \mathrm{min}^{-1}\right)$. A plot of $\left(t / q_{t(\exp )}\right)$ versus $t$ also produces a straight line with slope of $1 / q_{e(t h e o)}$ and intercept of $1 / k_{2} q_{e}^{2}$ (theo). This indicates the applicability of pseudo-second order model. Figures 10-13 present pseudo-second order kinetics for the adsorption of $\mathrm{Cr}(\mathrm{VI})$ onto TAGOC, STGOC, ZTGOC, and CAC respectively.

\section{Table III}

\section{Freundlich adsorption isotherm constants}

\begin{tabular}{l|c|c|c|} 
Carbon & $\begin{array}{c}\text { Adsorption capacity } \\
\boldsymbol{K}_{\boldsymbol{F}}(\mathbf{m g} \mathbf{g})\end{array}$ & $\begin{array}{c}\text { Adsorption intensity } \\
\mathbf{n}\end{array}$ & $\mathbf{R}^{\mathbf{2}}$ \\
\hline TAGOC & 15.42 & 1.01 & 0.9876 \\
STGOC & 21.40 & 1.19 & 0.9984 \\
ZTGOC & 20.42 & 1.13 & 0.9988 \\
CAC & 15.22 & 1.42 & 0.9981 \\
\hline
\end{tabular}

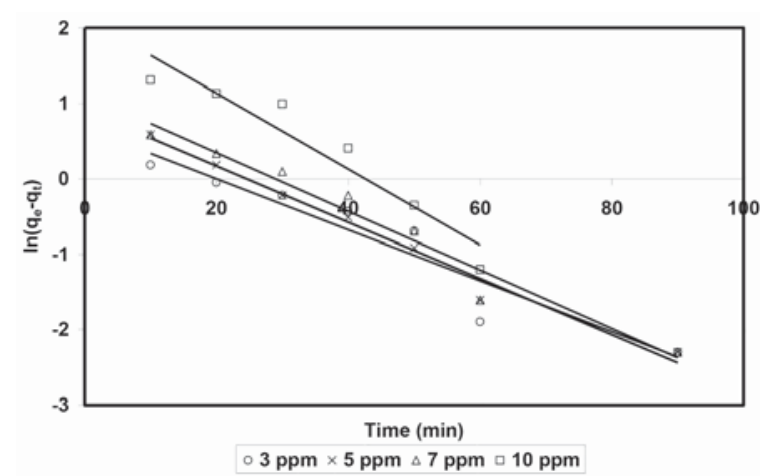

Figure 6-Pseudo-first order kinetic plot for adsorption of $\mathrm{Cr}(\mathrm{VI})$ onto TAGOC. $T 30 \pm 2^{\circ} \mathrm{C}, \mathrm{pH} 2.0 \pm 0.1$, adsorbent dose $0.25 \mathrm{~g}$ per $100 \mathrm{~mL}$

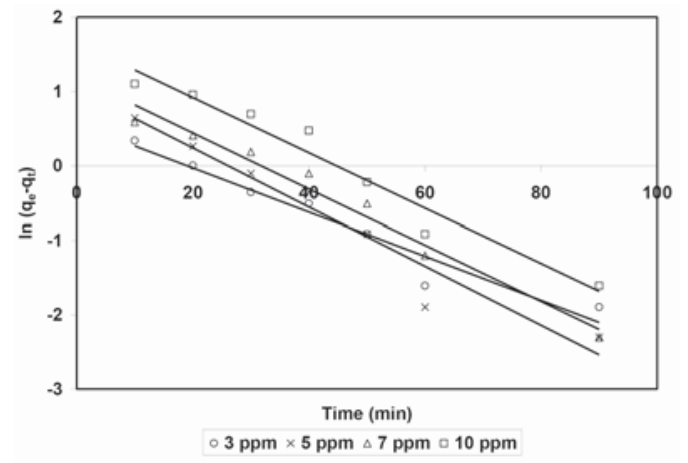

Figure 7-Pseudo-first order kinetic plot for adsorption of $\mathrm{Cr}(\mathrm{VI})$ onto STGOC. $T 30 \pm 2^{\circ} \mathrm{C}, \mathrm{pH} 2.5 \pm 0.1$, adsorbent dose $0.2 \mathrm{~g}$ per $100 \mathrm{~mL}$

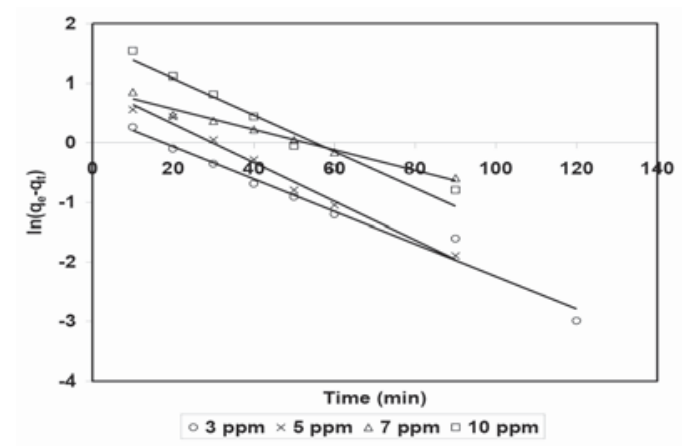

Figure 8-Pseudo-first order kinetic plot for adsorption of $\mathrm{Cr}(\mathrm{VI})$ onto ZTGOC. $T 30 \pm 2^{\circ} \mathrm{C}, \mathrm{pH} 2.5 \pm 0.1$, adsorbent dose $0.2 \mathrm{~g}$ per $100 \mathrm{~mL}$

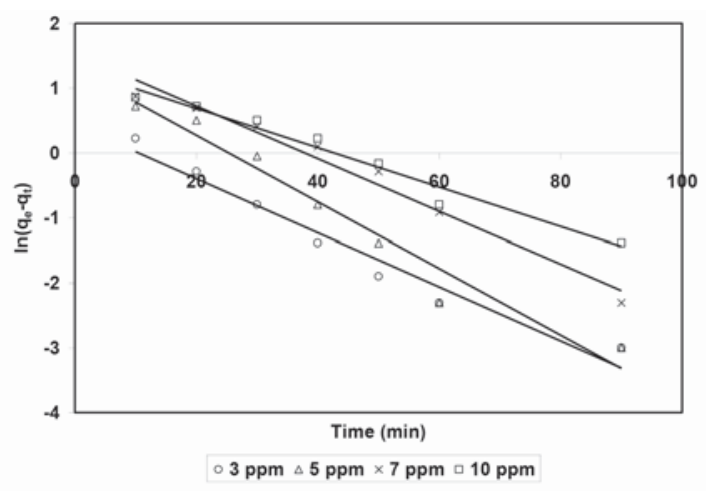

Figure 9-Pseudo-first order kinetic plot for adsorption of $\mathrm{Cr}(\mathrm{VI})$ onto CAC. $T 30 \pm 2^{\circ} \mathrm{C}, \mathrm{pH} 1.5 \pm 0.1$, adsorbent dose $0.3 \mathrm{~g}$ per $100 \mathrm{~mL}$ 


\section{Evaluation of chromium (VI) removal by carbons derived from Sesamum indicum oil cake}

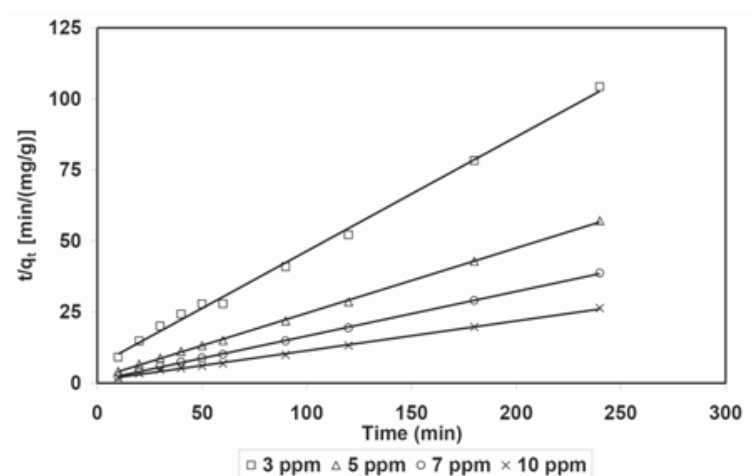

Figure 10-Pseudo-second order kinetic plot for adsorption of $\mathrm{Cr}(\mathrm{VI})$ onto TAGOC. $T-30 \pm 2^{\circ} \mathrm{C}, \mathrm{pH} 2.0 \pm 0.1$, adsorbent dose $0.25 \mathrm{~g}$ per $100 \mathrm{~mL}$

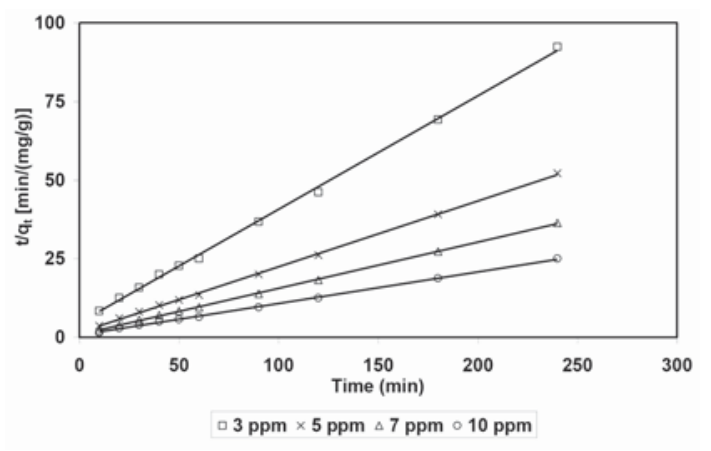

Figure 11-Pseudo-second order kinetic plot for adsorption of $\mathrm{Cr}(\mathrm{VI})$ onto STGOC. $T 30 \pm 2^{\circ} \mathrm{C}$, pH $2.5 \pm 0.1$, adsorbent dose $0.2 \mathrm{~g}$ per $100 \mathrm{~mL}$

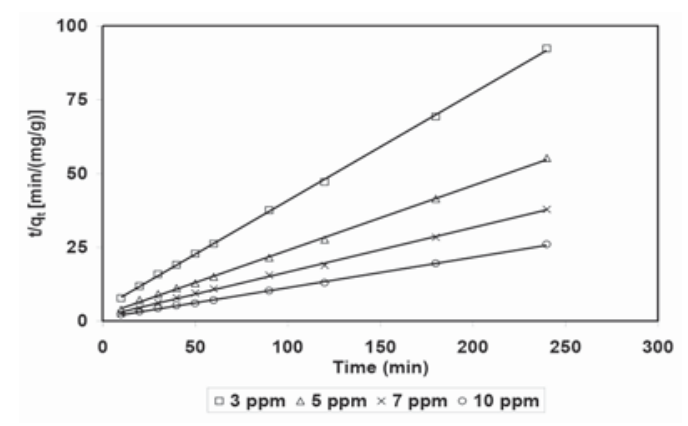

Figure 12-Pseudo-second order kinetic plot for adsorption of $\mathrm{Cr}(\mathrm{VI})$ onto ZTGOC. $T 30 \pm 2^{\circ} \mathrm{C}$, pH $2.5 \pm 0.1$, adsorbent dose $0.2 \mathrm{~g}$ per $100 \mathrm{~mL}$

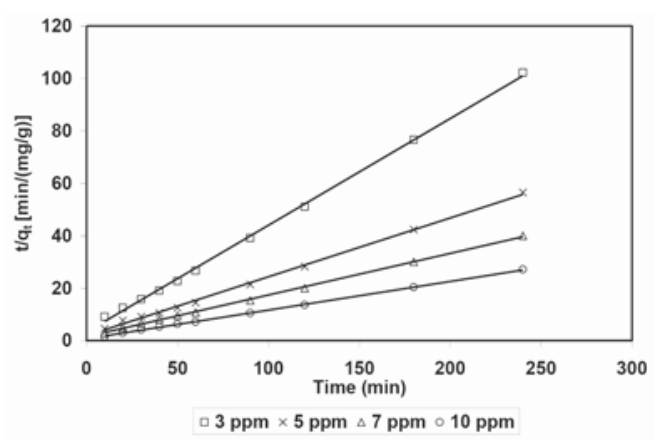

Figure 13-Pseudo-second order kinetic plot for adsorption of $\mathrm{Cr}(\mathrm{VI})$ onto CAC. $T 30 \pm 2^{\circ} \mathrm{C}, \mathrm{pH} 1.5 \pm 0.1$, adsorbent dose $0.3 \mathrm{~g}$ per $100 \mathrm{~mL}$
In order to compare quantitatively the applicability of kinetic models in fitting to the data, the percentage relative deviation $(P)$, was calculated as per the following expression.

$$
P=\frac{100}{N}\left\{\Sigma \frac{\left\{q_{e(\text { exp })}\right\}}{q_{e(\exp )}}\right\}
$$

where $q_{e(\exp )}$ is the experimental value of $q_{e}$ at any value of $C_{e}, q_{e(t h e o)}$ is the corresponding theoretical value of $q_{e}$, and $N$ is the number of observations. It is found that the lower the value of percentage deviation $(P)$, the better the fit. It is generally accepted that when $P$ is less than 5 , the fit is considered to be excellent (Ayranci and Duman, 2005). The results have been analysed using Equations [6] and [7]. The experimental data fits well in both of the equations. The values of $q_{e(t h e o)}$ calculated from these models are compared with experimental values $q_{e(\exp )}$ and are presented in Table IV. The theoretical $q_{e}$ values $\left(q_{e(t h e o)}\right.$ calculated from the pseudo-first order kinetic model differed appreciably from the experimental values $q_{e(e x p)}$. The percentage relative deviation $(P)$ was also very high. On the other hand, values of $q_{e(t h e o)}$ were very close to $q_{e}(\exp )$ when the pseudo-second order rate equation was applied. Furthermore, the percentage relative deviation $(P)$ was well within the range and the correlation coefficients $\left(\mathrm{R}^{2}\right)$ were very close to unity in pseudo-second order kinetics. These results clearly indicate that the adsorption of $\mathrm{Cr}(\mathrm{VI})$ onto these adsorbents is governed predominantly by pseudo-second order kinetics and that the rate-limiting step is governed by chemisorption between the carbon and chromium ions.

\section{Thermodynamic studies}

In order to understand whether the adsorption process is spontaneous or non-spontaneous, the value of free energy of adsorption $\left(\Delta G^{0}\right)$ is calculated by the following equation:

$$
\Delta G^{o}=-R T \ln a
$$

where $R$ is the universal gas constant $\left(8.314 \mathrm{~J} \mathrm{~mol}^{-1} \mathrm{~K}^{-1}\right), T$ is the absolute temperature $(K)$ and ' $a$ ' is the Langmuir constant representing energy of adsorption. Gibbs free energy changes $\left(\triangle G^{\circ}\right)$ for TAGOC, STGOC, ZTGOC, and CAC were calculated to be $-20.98 \mathrm{~kJ} / \mathrm{mol},-24.67 \mathrm{~kJ} / \mathrm{mol},-23.89 \mathrm{~kJ} / \mathrm{mol}$, and $-21.53 \mathrm{~kJ} / \mathrm{mol}$ respectively. The negative values of $\Delta G^{0}$ obtained for all the adsorbents indicate the feasibility and spontaneous nature of adsorption (Riaz et al., 2009; Acharya et al. 2009).

\section{Desorption studies}

Desorption studies were conducted with both acid $(\mathrm{HCl}$ and $\mathrm{HNO}_{3}$ ) and alkali $(\mathrm{NaOH})$ solutions. Various concentrations, $(0.2-2.0 \mathrm{~N})$ of $\mathrm{HCl}, \mathrm{HNO}_{3}$, and $\mathrm{NaOH}$ were used to desorb $\mathrm{Cr}(\mathrm{VI})$ from spent sorbents. The $\mathrm{pH}$ of the $\mathrm{Cr}(\mathrm{VI})$ solutions was maintained at 2.0 in the case of TAGOC, 2.5 in the case of STGOC and ZTGOC, and 1.5 in the case of CAC. The carbons and solutions were agitation for 2.5 hours (TAGOC), 2 hours (STGOC and ZTGOC), and 3 hours (CAC) in a horizontal mechanical shaker. $\mathrm{NaOH}$ was found to be a better desorbent than $\mathrm{HCl}$ and $\mathrm{HNO}_{3}$, and maximum desorption occurred at $1 \mathrm{~N} \mathrm{NaOH}$. Hence, various concentrations of $\mathrm{NaOH}$ $(0.01-1 \mathrm{~N})$ were used to desorb $\mathrm{Cr}(\mathrm{VI})$ from $\mathrm{Cr}(\mathrm{VI})$-loaded adsorbents. Results of desorption studies showed that about $46.2 \%, 30 \%, 38 \%$, and $60 \%$ of $\mathrm{Cr}(\mathrm{VI})$ could be desorbed from 


\section{Evaluation of chromium (VI) removal by carbons derived from Sesamum indicum oil cake}

\begin{tabular}{|c|c|c|c|c|c|c|c|c|c|c|c|}
\hline \multirow[t]{2}{*}{ Adsorbent } & \multirow{2}{*}{$\begin{array}{l}\text { Conc. } \\
\text { (mg/L) }\end{array}$} & \multicolumn{5}{|c|}{ Pseudo-first-order kinetics } & \multicolumn{5}{|c|}{ Pseudo-second-order kinetics } \\
\hline & & $\begin{array}{c}k_{1} \\
\left(\min ^{-1}\right)\end{array}$ & $\begin{array}{l}q_{e(t h e o)} \\
(\mathrm{mg} / \mathrm{g})\end{array}$ & $\begin{array}{l}q_{e(\exp )} \\
(\mathrm{mg} / \mathrm{g})\end{array}$ & $\begin{array}{c}\mathrm{R}^{2} \\
\text { (g/mg/min) }\end{array}$ & $\begin{array}{c}P \\
(\mathrm{mg} / \mathrm{g})\end{array}$ & $\begin{array}{c}k_{2} \\
(\mathrm{mg} / \mathrm{g})\end{array}$ & $q_{e(t h e o)}$ & $q_{e(\exp )}$ & $\mathbf{R}^{2}$ & $P$ \\
\hline TAGOC & 10 & 0.050 & 2.141 & 9.10 & 0.913 & 76.47 & 0.0120 & 9.551 & 9.10 & 0.998 & 4.86 \\
\hline TAGOC & 7 & 0.039 & 1.121 & 6.20 & 0.961 & 81.93 & 0.0279 & 6.386 & 6.20 & 0.999 & 2.99 \\
\hline TAGOC & 5 & 0.037 & 0.913 & 4.20 & 0.982 & 78.27 & 0.0305 & 4.369 & 4.20 & 0.999 & 4.02 \\
\hline TAGOC & 3 & 0.034 & 0.674 & 2.30 & 0.908 & 70.68 & 0.0263 & 2.486 & 2.30 & 0.997 & 8.07 \\
\hline STGOC & 10 & 0.037 & 1.659 & 9.60 & 0.956 & 82.71 & 0.0146 & 9.950 & 9.60 & 0.999 & 3.65 \\
\hline STGOC & 7 & 0.038 & 1.192 & 6.60 & 0.973 & 81.94 & 0.0251 & 6.803 & 6.60 & 0.999 & 3.07 \\
\hline STGOC & 5 & 0.040 & 1.033 & 4.60 & 0.945 & 77.55 & 0.0288 & 4.780 & 4.60 & 0.999 & 3.91 \\
\hline STGOC & 3 & 0.030 & 0.561 & 2.60 & 0.946 & 78.42 & 0.0284 & 2.773 & 2.60 & 0.999 & 6.66 \\
\hline ZTGOC & 10 & 0.031 & 1.688 & 9.25 & 0.948 & 81.76 & 0.0104 & 9.709 & 9.25 & 0.999 & 4.96 \\
\hline ZTGOC & 7 & 0.017 & 0.911 & 6.35 & 0.980 & 85.65 & 0.0149 & 6.649 & 6.35 & 0.999 & 4.71 \\
\hline ZTGOC & 5 & 0.033 & 0.968 & 4.35 & 0.988 & 77.74 & 0.0234 & 4.564 & 4.35 & 0.999 & 4.92 \\
\hline ZTGOC & 3 & 0.027 & 0.479 & 2.60 & 0.974 & 81.58 & 0.0301 & 2.751 & 2.60 & 0.999 & 5.81 \\
\hline $\mathrm{CAC}$ & 10 & 0.030 & 1.293 & 8.85 & 0.968 & 85.39 & 0.0177 & 9.132 & 8.85 & 0.999 & 3.19 \\
\hline CAC & 7 & 0.041 & 1.536 & 6.00 & 0.975 & 74.41 & 0.0172 & 6.297 & 6.00 & 0.999 & 4.95 \\
\hline CAC & 5 & 0.051 & 1.295 & 4.25 & 0.959 & 69.52 & 0.0271 & 4.452 & 4.25 & 0.998 & 4.76 \\
\hline CAC & 3 & 0.042 & 0.435 & 2.35 & 0.962 & 81.50 & 0.0507 & 2.456 & 2.35 & 0.999 & 4.50 \\
\hline
\end{tabular}

TAGOC, STGOC, ZTGOC, and CAC respectively by using $1 \mathrm{~N}$ $\mathrm{NaOH}$ under optimal conditions. Similar results have been reported in desorption studies conducted on marine algal mass (Thirunavukkarasu and Palanivelu, (2007).

\section{Application to wastewater}

Experiments were conducted to determine the efficiency of the adsorbents for the removal of chromium from chromeplating industry wastewater. The chemical composition of the wastewater is presented in Table $\mathrm{V}$. The $\mathrm{pH}$ of the wastewater was 4.2. As the wastewater contained a high concentration of chromium $(320 \mathrm{mg} / \mathrm{L})$, it was diluted six times with distilled water before the adsorption experiments were carried out. The diluted wastewater was adjusted to $\mathrm{pH} 2.0$ for TAGOC, 2.5 for STGOC and ZTGOC, and 1.5 for CAC using dilute nitric acid. The effect of adsorbent dose on the removal of chromium was studied under optimum time and $\mathrm{pH}$ conditions. Figure 14 presents the removal of chromium as a function of sorbent dose for an initial chromium concentration of $53.33 \mathrm{mg} / \mathrm{L}$. It is observed that $99 \%$ removal of total chromium could be achieved by TAGOC, STGOC, ZTGOC, and CAC at sorbent dosages of $1.0 \mathrm{~g}, 0.6 \mathrm{~g}, 0.8 \mathrm{~g}$, and $1.2 \mathrm{~g}$ per $100 \mathrm{~mL}$ respectively. This indicates that TAGOC, STGOC, and ZTGOC outperform CAC by a factor of $1.2,2$, and 1.5 respectively. Furthermore, the amount of chromium remaining in the wastewater after adsorption was found to be $0.52 \mathrm{mg} / \mathrm{L}$ for TAGOC, $0.42 \mathrm{mg} / \mathrm{L}$ for STGOC, $0.47 \mathrm{mg} / \mathrm{L}$ for ZTGOC, and $0.54 \mathrm{mg} / \mathrm{L}$ for CAC, in all cases less than the $2 \mathrm{mg} / \mathrm{L}$ discharge limit (Sahu et al., 2008) for chromium.

\section{Conclusions}

1. Batch studies showed that $89.2 \%, 96.0 \%, 93.5 \%$, and $88.5 \%$ of $\mathrm{Cr}(\mathrm{VI})$ ions were removed from aqueous solution by TAGOC, STGOC, ZTGOC, and CAC at optimum $\mathrm{pH}$ values of 2.0,2.5, 2.5, and 1.5 and adsorbent doses of $0.25 \mathrm{~g}$ per $100 \mathrm{~mL}, 0.2 \mathrm{~g}$ per $100 \mathrm{~mL}, 0.2 \mathrm{~g}$ per $100 \mathrm{~mL}$, and $0.3 \mathrm{~g}$ per $100 \mathrm{~mL}$ in 2.5 hours, 2 hours, 2 hours, and 3 hours respectively. From these results it is clear that
Table $\mathrm{V}$

Removal efficiencies for different adsorbents from chrome plating wastewater (after dilution and $\mathrm{pH}$ adjustment)

\begin{tabular}{|l|c|r|r|r|r|}
\hline Parameter & $\begin{array}{c}\text { Amount before } \\
\text { treatment } \\
\text { (mg/L) }\end{array}$ & \multicolumn{4}{|c|}{$\begin{array}{c}\text { Amount after treatment } \\
\text { (mg/L) }\end{array}$} \\
\cline { 3 - 6 } & & TAGOC & STGOC & ZTGOC & CAC \\
\hline Cr (total) & 53.33 & 0.52 & 0.42 & 0.47 & 0.54 \\
Sulphates & 46.67 & 38.60 & 36.20 & 37.00 & 40.60 \\
Iron & 1.17 & 0.02 & 0.01 & 0.02 & 0.08 \\
\hline
\end{tabular}

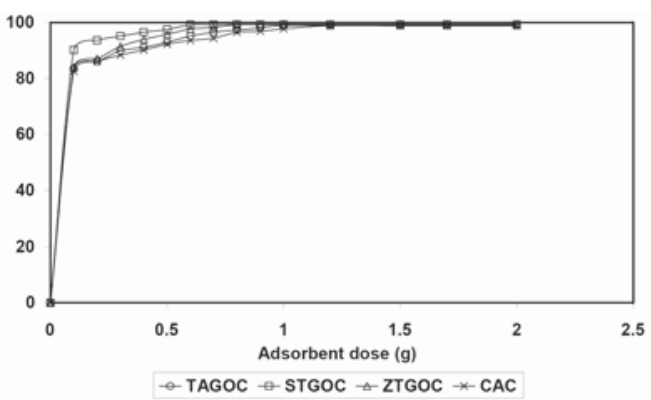

Figure 14-Effect of adsorbent dose on the removal of chromium from wastewater. [CrVltotal] $53.33 \mathrm{mg} / \mathrm{L}$, equilibration time $2.5 \mathrm{~h}$ for TAGOC, $2 \mathrm{~h}$ for STGOC and ZTGOC, $3 \mathrm{~h}$ for CAC

carbons derived from gingelly oil cake were more efficient than $\mathrm{CAC}$ at removing $\mathrm{Cr}(\mathrm{VI})$ ions from aqueous solutions at a higher $\mathrm{pH}$, shorter contact time, and with a lower adsorbent dose.

2. Both Langmuir and Freundlich adsorption isotherms fitted well with the experimental data. Since the R2 values for the Freundlich and Langmuir isotherms are almost equal, it may be concluded that both isotherms operate simultaneously on the surface of carbon adsorbents.

3. Langmuir adsorption capacity shows that TAGOC, STGOC, and ZTGOC are superior to CAC. 


\section{Evaluation of chromium (VI) removal by carbons derived from Sesamum indicum oil cake}

4. The adsorption of $\mathrm{Cr}(\mathrm{VI})$ onto TAGOC, STGOC, ZTGOC, and CAC was found to follow pseudo-second order kinetics.

5. Batch studies indicated that TAGOC is 1.2 times, STGOC is 2 times, and ZTGOC is 1.5 times superior to CAC in the removal of chromium from synthetic chrome plating wastewater based on the adsorbent consumption rates.

6. Desorption studies indicated that, about $46.2 \%, 30 \%$, $38 \%$, and $60 \%$ of $\mathrm{Cr}(\mathrm{VI})$ could be desorbed from TAGOC, STGOC, ZTGOC, and CAC respectively by using $1 \mathrm{~N} \mathrm{NaOH}$ under optimum conditions.

\section{Acknowledgements}

The authors thank Shri. D. Ravichandar, CEO M/s. JSW Steel Limited, Salem Works, for granting permission and providing facilities to carry out this research work in JSW's R\&D centre. The authors are also thankful to Professor Wahida Banu, Principal, Government College of Engineering, Salem, for providing facilities for this work.

\section{References}

Acharya, J., SAHU, J.N., Mohanty, C.R., and MEIKAP., B.C. 2009, Removal of lead(II) from wastewater by activated carbon developed from Tamarind wood by zinc chloride activation. Chemical Engineering Journal, vol. 149. pp. 249-252.

Ahalya, N., Kanamadi, R.D., and Ramachandra, T.V. 2010. Removal of hexavalent chromium using coffee husk. International Journal of Environmental Pollution, vol. 43, no. 1-2. pp. 106-116.

Ahalya, N., RamachandRa, T.V., and Kanamadi, R.D. 2003. Biosorption of heavy metals. Reserch Journal of Chemistry and Environment, vol. 7 , no. 4. pp. 71-74.

Alaerts, G.J., Jitjaturunt, V., and Kelderman, P. 1989. Use of coconut shellbased activated carbon for chromium(VI) removal. Water Science and Technology, vol. 21, no. 12. pp. 1701-1704.

Ayranci, E. and Duman, O. 2005. Adsorption behaviors of some phenolic compounds onto high specific area activated carbon cloth. Journal of Hazardous Materials, vol. 124, no. 1-3. pp. 125-132.

BARAL, S.S., DASA, S.N., and RATH, P. 2006. Adsorption of $\mathrm{Cr}$ (VI) using thermally activated weed Salvina cucullata. Biochemical Engineering Journal, vol. 31. pp. 245-255.

BARAN, A., BiçAK, E., BAYSAL, S.H., and OnAL, S. 2006. Comparative studies on the adsorption of $\mathrm{Cr}(\mathrm{VI})$ ions onto various sorbents. Bioresource Technology, vol. 98. pp. 661-665.

Dakiky, M., Khami, A., ManassRa, A., and Mereb, M. 2002. Selective adsorption of chromium(VI) in industrial wastewater using low cost abundantly available adsorbents. Advances in Environmental Research, vol. 6, no. 4. pp. 533-540.

Daneshwar, N., Salari, D., and Aber, S. 2002. Chromium adsorption and $\mathrm{Cr}$ (VI) reduction to trivalent chromium in aqueous solutions by soya cake. Journal of Hazardous Materials, vol. B94. pp. 49-61.

Das, D.D., Mahapatra, R., Pradhan, J., Das, S.N., and ThaKur, R.S. 2000. Removal of $\mathrm{Cr}(\mathrm{VI})$ from aqueous solution using activated cow dung carbon. Journal of Colloid and Interface Science, vol. 232, no. 2. pp. 235-240.

DE BRITO, K.C.T., CECCHINI, R., Rocha, J.A.V., and VARGAS, M.F.V. 2004. Mutagenicity of sediments and biomarkers of oxidative stress in fish from aquatic environments under the influence of tanneries. Mutation Research, vol. 561, no. 1-20. pp. 101-117.

Debnath, S. and Ghosh, U.C. 2008. Kinetics, isotherm and thermodynamics for $\mathrm{Cr}(\mathrm{III})$ and $\mathrm{Cr}(\mathrm{VI})$ adsorption from aqueous solutions by crystalline hydrous titanium oxide. Journal of Chemical Thermodynamics, vol. 40. pp. 67-68.

Donmez, D. and AKsu, Z. 2002. Removal of chromium(VI) from saline wastewaters by Dunaliella species. Process Biochemistry, vol. 38, no. 5 . pp. 751-762.

ERDEN, E., Karapinar, N., and Donat, R. 2004. The removal of heavy metal cations by natural zeolites. Journal of Colloid and Interface Science, vol. 280. pp. 309-314.

ESALAH, J. and HusEIN, M.M. 2008. Removal of heavy metals from aqueous solutions by precipitation-filtration using organophosphorus ligands. Separation Science and Technology, vol. 43, no. 18. pp. 3461-3475.

FreundLich, H. and Helle, W.J. 1939. Rubber die adsorption in Lusungen. Journal of the American Chemical Society, vol. 61. pp. 2-28.

Groffman, A., Peterson, S., and Brookins, D. 1992. Removing lead from wastewater using zeolites. Journal of Water and Environment Technology, vol. 5. pp. 54-59.

GuPTA, V.K., RASTOGI, A., and NAYAK, A. 2010. Adsorption studies on the removal of hexavalent chromium from aqueous solution using a low cost fertilizer industry waste material. Journal of Colloid and Interface Science, vol. 342. pp. 135-141.
GuPTA, V.K., SRIVASTAVA, A.K., and Jain, N. 2001. Biosorption of chromium(VI) from aqueous solutions by green algae Spirogyra species. Water Research, vol. 35. pp. 4079-4082.

HAssler, J.W. 1974. Purification with Activated Carbon. Chemical Publishing Co. Inc., New York. pp. 169-170.

Hema, M. and SRinivasAn, K. 2010. Evaluation of coconut oil cake carbon: equilibrium and kinetic studies. Asian Journal of Chemistry, vol. 22, no. 4. pp. 2965-2981.

Ho, Y.S. and McKAY, G. 1999. Pseudo second order model for sorption processes. Process Biochemistry, vol. 34. pp. 451-465.

Kadirvelu, K., Faur-Brasouet, C., and le Cloirec, P. 2000. Removal of $\mathrm{Cu}(\mathrm{II})$, $\mathrm{Pb}(\mathrm{II})$ and $\mathrm{Ni}(\mathrm{II})$ by adsorption onto activated carbon cloths. Langmuir vol. 16, no. 22. pp. 5404-8409.

Kadirvelu, K., Goel, J., and Rajagopal, C. 2008. Sorption of lead and cadmium ions in muticomponent system using carbon aerogel as adsorbent. Journal of Hazardous Materials, vol. 153, no. 1-2. pp. 502-507.

Kannan, A. and Thambidurai, S. 2008. Comparative studies on the removal of nickel(II) from aqueous solution by using carbon derived from palmyra palm fruit seeds and commercial activated carbon. International Journal of Science \& Technology, vol. 1, no. 1. pp. 93-107.

LAGERGREN, S. 1898. About the theory of so called adsorption of soluble substances. Kungliga Svenska Vetenskapsakad emiens Handlingar Band, vol. 24, no. 4. pp. 1-39.

LANGMUIR, I. 1918. The adsorption of gases on plane surfaces of glass, mica and platinum. Journal of the American Chemical Society, vol. 40. pp. 1361-1367.

LI, K., ZHENG, Z., and Li, Y. 2010. Characterization and lead adsorption properties of activated carbons prepared from cotton stalk by one step $\mathrm{H}_{3} \mathrm{PO}_{3}$ activation. Journal of Hazardous Materials, vol. 181, no. 1-3. pp. 440-447.

MAchidA, M., Mochimaru, T., and TATsumoto, H. 2006. Lead(II) adsorption onto graphene layer of carbonaceous materials in aqueous solution. Carbon, vol. 44 , no. 13 . pp. $2681-2688$.

Pandey, A., Anupam., S., and RAY, L. 2009. Uptake and recovery of lead by agarose gel polymers. American Journal of Biochemistry and Biotechnology, vol. 5, no. 1. pp. 14-20

PARK, S.J. and JUnG, W.Y. 2001. Adsorption behaviors of chromium(III) and chromium(VI) on electroless Cu-plated activated carbon fibers. Journal of Colloid and Interface Science, vol. 243, no. 2. pp. 316-320.

Perez-Aguilar, N.V., Muñoz-Sandoval, E., Diaz-Flores, P.E., and RangelMENDEZ, J.R. 2010.) Adsorption of cadmium and lead onto oxidised nitrogen-doped multiwall carbon nanotubes in aqueous solution: equilibrium and kinetics. Journal of Nanoparticle Research, vol. 12, no. 2. pp. 467-480.

Rao, R.A., Khan, M.A., and Jeon, B.H. 2010. Utilisation of carbon derived from mustard oil cake (CMOC) for the removal of bivalent metal ions: Effect of anionic surfactant on the removal and recovery. Journal of Hazardous Materials, vol. 173. pp. 273-282.

Riaz, M., Nadeem, R., Hanif, M.A., Ansari, T.M., and Rehman, K.U. 2009. Pb(II) biosorption from hazardous aqueous streams using Gossipium hirsutum (cotton) waste biomass. Journal of Hazardous Materials, vol. 161. pp. 88-94.

RodRIGUES, L.A. and SILVA, M.L.C.P. 2009. An investigation of phosphate adsorption from aqueous solution onto hydrous niobium oxide prepared by co-precipitation method. Colloids and Surfaces A, vol. 334 pp. 191-196.

Rukmangathan, M. and Kumar, V.S. 2009. Removal of chromium(VI) from water by using activated carbon obtained from butter oil cake. Asian Journal of Chemistry, vol. 21, no. 7. pp. 5273-5276.

Sahu, S.K., Verma, V.K., Bagchi, D., Kumar, V., and Pandey, B.D. 2008 Recovery of chromium(VI) from electroplating effluent by solvent extraction with tri-n-butyl phosphate. Indian Journal of Chemical Technology, vol. 15. pp. 397-402.

SHARMA, D.C. and Forster, C.F. 1995. Column studies into the adsorption of chromium(VI) using sphagnum moss peat. Bioresource Technology, vol. 52 , no. 3. pp. 261-267.

SRinivasan, K., Balasubramanian, N., and Ramakrishna, T.V. 1988. Studies on chromium removal by rice husk carbon. Indian Journal of Environmental Health, vol. 30, no. 4. pp. 376-387.

SRINIVASAN, K. and HEMA, M. 2009. Removal of Ni(II) from plating wastewater by activated carbon developed from neem oil cake. Indian Journal of Environmental Protection, vol. 29, no. 6. pp. 488-498.

SRIVASTAVA, S.K. GuPTA, V.K., and MohAN, D. 1996. Kinetic parameters for the removal of lead and chromium from wastewater using activated carbon developed from fertilizer waste material. Environmental Modelling and Assessment, vol. 1, no. 4. pp. 281-283.

ThirunavukKarasu, E. and Palanivelu, K. 2007. Biosorption of Cr(VI) from plating effluent using marine algal mass. Indian Journal of Biotechnology, vol. 6. pp. 359-364

UmESH, K., GARG, U.K., KAUR, M.P., GARG, V.K., and Sud, D. 2007. Removal of hexavalent chromium from aqueous solution by agricultural waste biomass. Journal of Hazardous Materials, vol. 140, no. 1-2. pp. 60-68.

Velizarova, E., Ribeiro, A.B., and OtTosen, L.M. 2002. A comparative study on $\mathrm{Cu}, \mathrm{Cr}$ and As removal from CCA-treated wood waste by dialytic and electrodialytic processes. Journal of Hazardous Matererials, vol. 94, no. 2. pp. 147-160.

Zou, W., ZHu, G., Huo, H., and Oıu, S. 2009. Effective heavy metal removal through porous stainless steel-net supported low siliceous Zeolite ZSM-5 membrane. Microporous and Mesoporous Materials, vol. 124, no. 1-3. pp. 70-75. 